\title{
Register van zaken
}

Zeeland, P. Van zie Van Zeeland

aardolie 101, 246, 262, 317, 319, 431, 530

ABDA Command 261-3

AMACAB 407, 457-8, 489

Ambarawa 379, 411-3, 428

Ambon 2, 13-4, 16-7, 19, 24, 26-8, 31, 33, 35-8, 47-8, 50-2, 78-9, 83, 93, 108, 140, $143,202,262,277,293,378,542,657$, 660, 686, 695, 697-700, 703-6, 708-9, $725,738,743,749$

Ambonezen 17, 27-8, 89, 378, 388, 397, 400, 402, 411, 413, 415, 423, 435-6, 468, 515, 517, 656-7, 659, 686, 691, 696-8, 700, 703-5, 708-9

Angkatan Pemoeda Indonesia (API) 381, 444

Angkatan Perang Republik Indonesia (APRI) 708

Angkatan Perang Republik Indonesia Serikat (APRIS) 690, 692, 696-7, 699700

Anti-Revolutionaire Partij (ARP) 178, 190, 208, 223, 367, 442, 463, 510, 529, $536,582,584-5,602,669,721,744,748$ APRA-affaire zie Westerling-affaire Arabië 14, 19, 26, 42, 45, 53, 58, 410, 606 Arabieren 129, 131, 133, 138, 170, 191, 211, 220, 254, 291, 295, 315, 342, 479

Asrama Angkatan Baroe 307, 327, 333, 382

Asrama Indonesia Merdeka 327, 333, 348

assistent-resident 77

Atjeh 9, 11, 17, 24-5, 40, 43, 61, 80, 87, $89,91,97,100,277,402,437,604,630$,
$635,725,742$

- Atjeh-oorlog 97-9, 103, 111-3, 117-20, 123-5, 158, 178

Atlantisch Handvest 256, 313

Australië xx, 50, 202-3, 232, 248-9, 2602, 264, 266, 276-8, 291, 297, 299, 301, $304,321-5,335,337-41,344,356-7,369$, 371-2, 380, 386-8, 396-7, 399, 418-9, 431, 437, 456-7, 515-6, 532, 534, 540, 554-5, 560-1, 576, 578, 605-8, 721, 726, 744-6, 749

Badan Keamanan Rakjat (BKR) 374, 377, 404-5, 411, 413-4

Balai Poestaka 142

Balambangan 10-1, 59

Bali 6-7, 9-10, 23, 36, 59, 87, 90, 109, 124, 128, 237, 263-4, 277, 312-3, 332, 378, $418,447,457,512,519$

Banda-eilanden 14, 16, 24, 28, 35-6, 48, 204-5, 213, 239, 261, 359, 718

Bandjermasin 59, 61-2, 90, 125, 378

Bandoeng 102, 133, 143, 161, 164-5, 185, 197-8, 204, 206, 215, 219, 245, 248, 263, 265-7, 292, 294, 307, 324, 327, 334, 359, 379-80, 396-7, 401-2, 406, 411, 435, 4468, 469-71, 534, 546, 574-5, 583-4, 593, $669,686,691-4,709,719,723,725-7$, 739

Bangka 59, 79, 101, 447, 467, 542, 606-7, $622,631,635-8,642$

Banjoewangi 471, 553

Bantam (gebied en stad) 4, 9, 11, 17, 234, 27, 31-2, 43, 109, 174, 190, 198, 201, $265-6,553,603$ 
Bantam (sultanaat) 2, 11, 17, 20, 23-4, 312, 41-3, 47-8, 71-2

Barisan Pelopor 327-8, 334, 347, 382, 399, 448

Batakgebieden 125

Batavia

- stichting 31-3

- betekenis van de naam 32, 65

Bataviaasch Genootschap voor Kunsten en Wetenschappen xix, 58, 73, 92, 108 batig slot $68,84-6,89,95-7,116$

Bekasi 402, 470

Benkoelen 43, 80, 87, 239, 253, 297, 306

Benteng Repoeblik 511-2, 569, 572

benteng-stelsel $82-3$

bersiap-terreur 400-3, 448, 459-60, 504, $531,574,689,694,706,737$

bestand tussen Nederland en de Republiek Indonesië

- eerste bestand (1946) 478-81, 519-20, $532,552-3,556,587,648$

- tweede bestand (1948) 562-6, 590, 601, $603,626,648$

- derde bestand (1949) 647-51

Biliton 59, 74, 80, 101, 104, 397

Binnenlands Bestuur (BB) 515, 527-8, 534,626

- inrichting 76-8, 131, 138, 189, 234, 237

- opleiding bestuursambtenaren 78, 131-2, 143, 145

Birma (dekolonisatie van) 232-4, 308, 310, 331, 370-1, 373, 388-90, 396, 474, $526,577,604,606,674$

Blitar 330-1, 404, 428

Brits-Indië 131-2, 146, 232-3, 243, 302, 364, 388

Boeginezen 40, 42, 46, 61, 73, 89

Boedi Oetomo 151-2, 158-60, 169-70, 172, 176-7, 183-4, 190, 197-8, 205-6, 216, 220, 229, 233, 331

bondgenootschappelijke rijken 48-9, $110,121-2$

Bondowoso 563

Boni $40-1,79,90,125$

Boven-Digoel 202-3, 225, 227, 230, 239, 250, 261, 278, 322, 387, 661

Buitenzorg (Bogor) 58, 78, 105, 138, 143, 189, 243, 265-6, 396-7, 401, 406, 435,
$447,470,488,520,532,534$

burgergeïnterneerden

- onder de Japanse bezetting 293-6

- na de Japanse bezetting 355-6, 371, 379-81, 384-5, 390-1, 396, 400-1, 406, 409-13, 415-7, 436, 459, 471, 474, 478-9, 540

Bijeenkomst voor Federaal Overleg (BFO) 583-4, 600, 602, 610, 622-3, 631, 633-6, 641, 644-6, 648, 653-4, 659, 6634, 667-71, 689, 695, 700

Ceram 13, 36, 38, 91, 128, 696, 704-5, 725,742

Ceylon 7, 13, 25, 33, 39, 41, 43, 45-6, 48, $50,52,54,57,61,67,69,73,108,264$, $321,372,381,384,389,430,527,606$

Charter van Soevereiniteitsoverdracht 665-7, 672, 680-1, 705-6

China 1, 3-7, 9-11, 14, 23, 26, 34, 42, 45, $58,62,110,123,157,188,199,202,230$, 240, 246, 249, 258, 278-9, 283, 310, 370, $383,450,560,595,716,731,743,749$

Chinezen xxi, 4, 33, 46, 49, 53-5, 58, 79, $84,92,103,129-31,133,138,142,151$, 158, 164, 170, 174-6, 184, 191, 201, 211, 220, 254, 25?, 280, 291, 295-6, 309, 315, $318,332,342,364,387,401,423,446$, 459-60, 479, 560, 716

chinezenmoord (1740) 53-4

Christelijk-Historische Unie (CHU) 463, 510, 536, 581-2, 585, 599, 602, 662-4, $669,680,721,744$

Comité Boemi Poetra 161-4

Commissie-Carpentier Alting 173-4, 186, 190, 208, 241, 244, 407, 410

Commissie-Generaal (1793-1799) 61-2

Commissie-Generaal (1815-1818) 74-6

Commissie-Generaal (1946-1948) 471-5, 478-85, 500, 507-9, 513, 520-2, 524, 529, 532-5, 539-41, 546, 549, 551, 555, 563, 709-10

Commissie van Goede Diensten (CGD, in 1947 ingesteld door de VN-

Veiligheidsraad) 560-2, 564-9, 578, 580-1, 583, 586-7, 590, 592-3, 599-601, $605,607-8,631$

Commissie-Nederburgh $69-70$ 
Commissie-Visman 252-4, 289, 341

Communistische Partij Nederland (CPN) 166, 188, 201, 223, 237, 365, 409, 455, $463,475-6,509,582,585,662-3,669$ controleur 53, 77, 131

coöperatoren zie non-coöperatiepolitiek Cultuurstelsel 67, 84-7, 95-6, 100

Daroel Islam/Darul Islam 572-3, 590, $627,676,692,724-6,742$

Deli 91, 100-2, 120, 277, 402

Denpasar (conferentie van) 512-4, 517, 661, 664

Depok 52, 401, 403

De Zeven Provinciën (schip) zie muiterij dienstplichtigen (Nederlandse) 358, 419, 453, 460, 468, 470, 475-7, 504, 509, 523, $529,536,543,587-8,597$

dienstweigeraars (Nederlandse) 476

Djakarta

- verovering door de VOC 31-2

- herstel van de naam 205, 242, 299

Djambi 40, 91, 125, 262, 604

Djawa Hokokai 315-7, 334, 344, 376

Djojobojo-legende 56, 82, 213, 249, 280, 691

'dodentrein' zie Bondowoso

Door de Eeuwen Trouw 704-5, 708

Door duisternis tot licht 157

Duitse bezetting van Nederland (19401945) 244-6, 337-8, 365-6, 391, 395, 478

Duitsers 45, 104-5, 129, 245, 258-61, 296

dwangarbeid 103-4, 133

East India Company (EIC) 28, 37, 43, 61$2,72,80,104,110,157$

Eed van de Jeugd 207

eerste Nederlands offensief (1947)

- aanloop 547-552

- verloop 552-5

- reactie Verenigde Naties 555-8

Empat Serangkai 299, 304, 308, 315-6

ethische politiek $68,114-7,123,141-2$, 146, 157, 164, 168, 170, 176, 211, 243

Europeanen (rechtsbegrip) 132-4, 142-3, $145-6,155,158,243,254,288,295,304$, 363

Excessennota 491,618 exorbitante rechten xvi, 134-6, 163, 166,188, 201, 215, 225

Expeditionaire Macht 336, 338-9, 418-20

federalisering van Indonesië

- opvattingen voor de Tweede

Wereldoorlog 178-9, 199, 215, 224

- bespreking bij voorbereiding Indonesische onafhankelijkheid 342

- Nederlandse keuze voor federalisering 431-4

- Indonesische aanvaarding in Linggadjati (1946) 483-4

- Nederlandse stappen tot federalisering (1947-1949) 466-7, 504, 506, 512-4, 543-4, 564, 573-8, 583, 598-600, 622, $629,639,643$

- Indonesische beëindiging van de federalisering (1950) 700-3

Filippijnen 2-3, 16, 25, 34, 37, 42-3, 123, $146,153,158,171-2,199,207,232-5$, 246, 248, 258, 261-2, 265, 276, 278-9, 283, 294, 302, 304, 308, 310, 331, 340, $342,364-5,383,408,474,525-6,542$, 577,595

Flores 13, 17, 59, 109, 123, 128, 225, 239, 696

Frankrijk 61-2, 67, 69, 72, 85, 110, 112-3, $115,246-7,362$, 390, 450-1, 525-6, 560, 687, 745

Front Demokrasi Rakjat (FDR) 572, 594-6

Gaboengan Politik Indonesia (Gapi) 239-42, 250, 253-6, 258-9, 281

Garoeda 6, 756

geconcentreerde linie $99,117-8$

geleide democratie 731, 741

Gerakan Rakjat Indonesia (Gerindo) 230-1, 236, 240, 242, 258, 264, 327, 378, 425,478

Goa 15, 17, 21

gouverneur-generaal 19, 26, 31, 33, 36, $43,47,49,52,57,62,70-2,74,77,84$, 120-2, 124, 131-2, 134-9, 144, 157, 161, 164, 169-70, 172-3, 179, 185, 191, 203-4, 207-8, 212, 215-6, 218, 220-2, 224, 227$8,236,239,245,247,250,253,255-7$, 259, 261, 263, 266-7, 286, 292-4, 297, 
$393,398,407$

Gowa 40-1, 43, 125

grondwet (Indonesië)

- eerste grondwet Republiek Indonesië

(1945) 342-3, 354, 360-1, 374-5, 421-2, $426,432,740$

- grondwet RVI (1949) 653-5, 659, 666-7, 671, 693

- voorlopige grondwet nieuwe Republiek Indonesië (1950) 701, 714, 730, 739-40

- terugkeer naar grondwet van 1945

740-1

grondwet (Nederland)

- eerste grondwet Koninkrijk der

Nederlanden (1815) 74

- grondwet van 1848 91, 134

- grondwet van 1922 174, 29-10, 235, $239,245,251,367,441,475,479$

- grondwet van 1948 581-2, 584, 662

- grondwet van 1956 733-4

Groot-Brittannië 73-4, 85, 110, 112-3, $128,153,212,232,241,247-8,257-8$, 261-3, 335, 338-40, 357, 362, 364-5, 3703, 383-6, 388-91, 393-5, 397-9, 404-7, 410-20, 430, 434-7, 439-40, 443, 445-50, 452-3, 458-60, 471, 474, 478-81, 488-9, 519-20, 526-7, 548, 554, 559, 576-7, 595, $687,742,745$

- conflicten met VOC 20, 28, 32, 61

- overname Kaapkolonie, Ceylon en VOC-vestigingen in India 62, 67, 69$70,73,80$

- bestuur over Java 72-3

- verdrag van 1824 met Nederland 80

- verdrag van 1871 met Nederland 97-8

- tijdelijk gezag over Indonesië (19451946) $355,370-2,458,469,488$

Grote Oost zie Oost-Indonesië

Grote Postweg 71

guerrilla 470, 474, 558, 588-90, 605, 621, $625-6,638,640,676$

haatzaai-artikelen xvi, 136-7, 166, 215

Handvest van Djakarta 342, 740

Heiho 294-5, 313-4, 349, 363, 376, 383-4, 401, 406-7

Hindoe-Indonesische culturen 5-7, 107
Hitoe 13, 26-7, 38

Hizboellah 328, 382, 572

Hoge Adviesraad 343, 360, 459, 575, 714, 740

Hoge Regering 47, 49, 54, 70

Hoge Veluwe conferentie 452-6, 459, $461,466,478$

hongi-tochten $38,59,76,78$

Ikada-terrein 382, 494

imperialisme 109-10, 212

India 1, 4-7, 15, 19, 31-2, 39-43, 45-6, 48, $50,58,61,67,73-4,80,110,113,131$, 168

- nationale beweging $157,182-3,366$, 375

- dekolonisatie 153, 157, 172-3, 179, 190, 232-5, 301, 364-5, 373, 388-9, 430, 474, $526-7,558,674-5$

- steun aan Republiek Indonesië 459, 532, 534, 554-5, 606

Indian Mutiny 110, 168

Indië Weerbaar-campagne 168-70, 175, 186,254

indigo 45, 84-5, 95

Indische Partij 161-4, 166, 175, 180-2, 184, 359

Indische Sociaal-Democratische Vereeniging (ISDV) 165-7, 169, 181, 186-7, 198

Indo-Europeanen xxi, 102, 129-30, 133, 146, 151, 160-1, 166, 175, 180-1, 211, 218, 245, 260, 286-7, 291, 296, 315-6, $318,342,363,400,402,423,435,446$, $459,531,661,700$

Indo-Europeesch Verbond (IEV) 180-1, 184, 208-9, 235

Indonesië

- betekenis van de term 2

- oorsprong van de term 105, 175-6

Indonesië Parlementair (campagne) 239$42,251,359$

Indonesisch Jeugdcongres (1928) 206-7

Indonesisch-Nederlandse Unie 482-4, 486, 503-4, 508, 511, 522-3, 532, 537, 540-1, 544, 568, 578, 582-3, 607, 612, $615,624,633,646,653,655,672,674$, 702, 705, 707, 709-13, 719-20, 722-4, 
$728,733-4$

Indonesisch Verbond van Studeerenden 176, 244

Inlanders (rechtsbegrip) 132-4, 138, 155, 221-2, 243, 304

islam 2, 9-11, 13-4, 17, 40, 83, 89, 97, 107, 151, 163-5, 184, 187, 189, 197, 206, 231, $244,313,328,332,341-3,360,399,572$, 740

\section{Itinerario 23}

Japan $14,19,24,26,31,34,45-6,48,58$, $62,123,133,153,168,199,212-3,219$, 230, 233, 238, 240-1, 246-7, 249, 716, 744

- voorbeeld voor Indonesische nationalisten 157-8, 230

- in oorlog met Nederland 257-9, 261-7, 276-8

- bezetter van Indonesië 281-99, 304-20, $325-8,361,382$

- wegbereider voor Indonesische onafhankelijkheid 325-7, 330-2, 341-5, 356, $360,368-9,372,394$

Japanners 133, 158, 257-60, 285-6

Java-oorlog 80-3

Javazee (zeeslag op de ) 263-4

Jogjakarta

- verplaatsing regeringszetel Republiek naar 436

- bezetting door Nederlandse troepen 603

- terugkeer Republikeinse regering in 607-8, 641-2

Jong-Sumatranen Bond 194, 207

Kaapkolonie 43, 48, 50, 52, 73

kabinetten in Indonesië

- presidentieel kabinet (1945) 376

- kabinetten Sjahrir (1945-1947) 426, $446,477-8$

- kabinet Amir Sjarifoeddin (1947-48) 550

- kabinetten Hatta (1948-1950) 569, 671

- kabinet Natsir (1950-1951) 704

- kabinet Sukiman (1951-1952) 715-6

- kabinet Wilopo (1952-1953) 716-7

- eerste kabinet Ali Sastroamidjojo
(1953-1955) 718-9

- kabinet Burhanuddin Harahap (19551956) 719

- tweede kabinet Ali Sastroamidjojo (1956-1957) 724

- kabinet Djuanda (1957-1959) 732-3

- tweede presidentieel kabinet (1959) 740

kabinetten in Nederland

- kabinetten Colijn (1933-1939) 223, 237

- kabinet Gerbrandy (1940-1945) 249

- kabinet Schermerhorn (1945-1946) 368-9

- eerste kabinet Beel (1946-1948) 463-5

- kabinetten Drees (1948-1958) 585, 707, 721, 733

- kabinet De Quay (1959-1963) 744

Kalidjati 265-7

Kandy 39, 48

Kantoor voor Volkslectuur zie Balai Poestaka

Karel Doorman (schip) 744-5

Katholieke Volkspartij (KVP) 443, 454, 463-5, 473, 505, 507-9, 529, 537-8, 547, 581, 584-6, 602, 634, 653-4, 662, 664, $669,721,744$

Kempeitai 287-9, 295, 305, 310, 323-4, 328-30, 348, 361, 414

Kerintii-vallei 125

kina 101-2, 105

KNIP zie Komite Nasional Indonesia Poesat

Koetaradja 98-9, 117-9, 222, 277

koffie $19-20,45,53,59,70,73,75,84,96$, $101-2,317,530,553$

Koloniaal Instituut 114

koloniaal leger 68, 82-3, 89-91, 93, 99, $102,112,115,118-20,123-5,128,168-$ 9, 178, 199, 221, 224, 247-8, 275, 404, 471, 514, 528, 657, 691, 696, zie ook Koninklijk Nederlands-Indisch Leger koloniaal onderwijsbestel 142-7

koloniaal taalbeleid 140-2

koloniale troika 527, 530, 637

Komite Nasional Indonesia Poesat (KNIP) 375-6, 421-2, 426-7, 445-6, 4778, 511, 522, 524, 552, 570, 606, 642, 664, $668,672,701,714$ 
Koningsplein 71, 75, 78, 108, 285, 349, 382, 494

Koninklijk Instituut voor Taal-, Land- en Volkenkunde (KITLV) 107

Koninklijk Nederlands-Indisch Leger (KNIL) 224, 228, 247-8, 258, 262-6, 276-7, 279-80, 292, 321-2, 324-5, 335, 337-9, 387-8, 396-7, 401, 404-6, 419-20, 435-8, 447-8, 454, 456-7, 466, 468-9, $480,505,513,515-7,527-9,534,579$, $587,626,629,646,655,657,690-2,695-$ 700, 708, 726

Koninklijke Paketvaart Maatschappij (KPM) 100, 118, 260, 387-8, 398-9, 705, 708, 726, 736, 738

konsepsi 732, 735, 739

Konstituante (1956-1959) 701, 730, 73940

Korte Verklaring 121-2

kruidnagelmonopolie $37-8,75-6$

krijgsgevangenen (van Japan) 275, 285, 292-3, 296, 371, 379-81, 384-5, 390-1

Ksatrian Instituut 185, 198

landrente $67,73,77,84-6,116$

Lampong-gebied 43, 91, 93

leenroerige rijken 48-9, 110, 121

Linggadjati (akkoord van)

- totstandkoming 482-4

- aankleding 507-9

- Indonesisch verzet tegen akkoord 5102

- Nederlands verzet tegen akkoord 50910

- ondertekening 524

- interpretatie 504, 521-3, 533-5, 537, 541-4

Lombok 6, 10, 59, 109, 112-3, 124, 178, $332,371,396,403$

Madjelis Rakjat Indonesia (MRI) 256-7, 259, 281

Madioen 243, 572, 596, 605, 652

Madioenopstand 596-7, 599, 605, 626-7, $662-3,668,718$

Madoera 11, 23, 48, 56-7, 59, 282, 286-7, $299,471,534,556,563-4,573-4$

Magelang 82-3, 411-3, 428, 542
Makassar xviii, 17, 37, 40-1, 48, 59, 62, $83,125,287,311,362,378,458,466$, 512-8, 647, 650, 668, 695-8, 700-1, 709, 751

Malakka (sultanaat) 10-1, 15

Malino (conferentie van) 357, 466-7, 512, 514, 516, 523, 533, 541, 544, 643, 661

Manipol zie Politiek Manifest

marineblokkade van de Republiek 51920, 538, 546

Masjoemi/Masjumi 313-6, 328, 330, 334, 344, 425, 444-6, 477-8, 511, 524, 545, 562, 569-71, 573, 595, 605, 640, 668, 701, 714-9, 725, 729-30, 732, 738-9, 741

Mataram 2, 11, 20, 32-3, 40-3, 46, 48, 546, 81

Max Havelaar 93

Medan xviii, 102, 277, 362, 378, 380, 390, 396-7, 553

Menado 41, 59, 109, 262, 457, 657

Menadonezen 109, 118, 360, 397, 411, $415,423,468,656-7,695,700$

Menteng 31382

Merauke 128, 278, 661, 665, 686, 755

Midden-Java (strijd in oktober-november 1945) 401, 411-4, 417, 420, 426, 428, 435,446

Minahasa 109, 143, 175, 623, 656-60, 695, 703-4

Minahasa-bond 229, 240, 446, 514, 647

Minangkabau 40, 79, 87, 89, 100, 164, 184, 186, 194-5, 198-9, 201, 206, 235, 277,378

missie (rooms-katholieke) 108-9, 707

Modjopahit xv, 1, 7, 9-10, 14, 41-2, 154, 165

Moehammadiah/Muhammadiah 184, 206, 231, 280, 310, 314, 717

Molukken 2, 9, 13-4, 16-7, 19-20, 23-8, $31-2$, 35, 37-9, 41, 45, 50, 59, 67, 70, 72, 74-5, 78-9, 96, 109, 374, 378, 392, 454, 467, 524, 623, 656-61, 686, 695, 697-8, $700,703,708,725$

muilkorfcirculaire 136-7, 224

muiterij op De Zeven Provinciën 221-4, 237

muiterij in Makassar (1950) 696-8, 700

Nahdatoel Oelama/Nahdatul Ulama 
(NU) 206, 231, 314, 717-8, 724, 730

Nationaal Comité Handhaving Rijkseenheid 510, 536, 549, 584, 623, 658-60, 662, 703-4

nationale comités 220, 236, 242, 280, 284, $359,374-7,401,404,427$

Nationale Fractie 216, 218, 228-9, 235, 254

Nederlands-Indonesische Unie zie Indonesisch-Nederlandse Unie

Nederlandsche Handel-Maatschappij 76, 85-6, 93, 101

Nederlandse Militaire Missie (NMM) $656,699,712,718$

Negara Indonesia Timoer (NIT) zie Oost-Indonesië

Netherlands Forces Intelligence Service (NEFIS) 323-5, 393, 398, 421, 437, 726

Netherlands-Indies Civil Administration (NICA) 321-3, 336-40, 370-2, 385, 390, 396-9, 406-7, 431, 457, 489, 515-6

Nieuw-Guinea

- Nederlandse aanspraak op 87, 111-2, 123, 128

- in conferentie van Denpasar 513

- in RTC 660-6

- in 'ijskast' 707, 719, 745-6

- in AVVN 723-4, 735-6, 747-50

- militaire confrontatie 742-5, 751-3

- beëindiging conflict 751-4

non-coöperatiepolitiek 152, 182-3, 193, $198,203,206,216,219,228-31$

november-beloften 172-3, 177, 179, 183

Ondernemersraad voor NederlandschIndië 179, 192, 209, 237

onderwijs zie koloniaal onderwijsbestel en 'wilde scholen'

onthoudingsbeleid 87,89

ontvoering van Hatta en Soekarno 347-8

ontvoering van Sjahrir 461-2

Onze strijd 423-6, 429, 444

oorlogsmisdaden 36, 119-20, 278-9, 448, $491,517-8,563,589$

oorlogsvrijwilligers (Nederlandse) 3389, 356-7, 368, 397, 410, 419, 447-8, 468, $529,536,587$

Oost-Indonesië (deelstaat) 467, 512-4,
517-8, 533, 544, 556, 575-6, 579, 583, $609,643,645,661,664,666,668,694-8$, 701

Oost-Java (deelstaat) 539, 573-4, 643

Oost-Sumatra (deelstaat) 573-4, 583, 609, $643,695,701$

opium 45-6, 57, 70, 73, 79, 84, 138, 160

Opleidings School Voor Inlandse

Ambtenaren (OSVIA) 145, 163

ordonnanties 132, 191, 228, 251, 322, 398

pacificatie 122,419

Padang 40, 59, 61, 80, 87, 297, 378, 380, 390, 396-7, 738

Padjadjaran 9, 11

Padri-oorlog 79, 87-9

Palembang 7, 10, 40, 59, 62, 72, 79-80, 87, 91, 100, 262, 378, 380, 382, 396-7, 553

Pangkalpinang (conferentie van) 479 , 660

Pantja Sila 341-3

Papoea's 3, 109, 202-3, 335, 665, 747-8, 750

parlementsverkiezingen in Indonesië (1955) 426, 714, 729-30, 739-40

parlementsverkiezingen in Nederland

- (1933) 223

- (1937) 237, 418, 443

- (1946) 452, 460, 463

- (1948) 581-2, 588, 592, 658

- (1952) 720-1

- (1956) 733

- (1959) 744

Partai Boeroeh/Partai Buruh 511, 569, 572

Partai Indonesia (Partindo) 217-9, 224-5, 227-31, 233, 426

Partai Indonesia Raja (Parindra) 229-30, 236, 240, 242, 250, 290, 307

Partai Katolik Repoeblik Indonesia 425

Partai Keristen Indonesia (Parkindo) 425, 477, 698

Partai Komunis Indonesia (PKI) 140, 167, 181, 187-9, 195, 197-201, 204, 215, $425,445,511,580,594-6,714-5,717-8$, $724,730,735,739-41$

Partai Murba 597, 714

Partai Nasional Indonesia, opgericht in 
1927 (PNI) 204-7, 213-9, 280

Partai Nasional Indonesia, opgericht in 1946 (PNI) 425-6, 445-6, 477-8, 511, 524, 545, 569-71, 578, 640, 668, 714-9, 724, 729-30, 732, 735, 740

Partai Republik Indonesia (Pari) 202

Partai Sosialis (PS) 425, 444, 477, 511, 569, 572, 594

Partai Sosialis Indonesia (PSI) 572, 7146, 730, 741

Partij van de Arbeid (PVDA) 443, 453, 455, 463-5, 473, 475, 505, 507, 509, 537$8,547,552,554,562,581,585-6,598$, $602,604,633,653-4,662,664,669,721$, $737,743,746-8,753$

Pasoendan (deelstaat) 573-4, 583, 609-10, 627, 643, 692, 694

Pasoendan (vereniging) 159, 205, 216, 220, 233, 240

Pasoendan-affaire 543

Panitia Persiapan Kemerdekaan Indonesia (PPKI) 345, 347-9, 359-60, 374-5, 377, 381

Panitia Persiapan Nasional (PPN) 670-1, 673

Pantja Sila 341, 343

Pegangsaän Oost 56 349,354, 358, 436, 481, 500, 552, 556, 577, 590-1, 600, 650, 671, 673

Pembela Proklamasi (PP) 597, 627-8, 668

Pemerintah Revolusioner Republik Indonesia (PRRI) 738-9, 741-3

Pemoeda Sosialis Indonesia (Pesindo) 444-7, 462, 511, 572

Pendidikan Nasional Indonesia (PNI Baroe) 217-9, 225, 227-8, 230, 329, 425

Perhimpoenan Indonesia (PI) 193-8, 204-6, 210, 212, 215, 219, 223, 229, 237, 239, 280, 327, 359, 368, 370, 395, 409, 441, 714

Permesta-beweging 732, 738

Persatoean Perdjoeangan (PP) 445-6, 461, 511, 572

Persatoean Timur Besar (PTB) 657-9, 698, 703

Perzië 1, 5, 14, 26, 34, 42-3, 45, 48, 50, 58

Peta 311-3, 315, 328, 330-1, 334, 347-8, $361,374,381-2$, 399, 404-5, 411, 427-8,
469

petitie-Soetardjo 234-9, 251, 359, 365, 514, 673

PID zie Politieke Inlichtingen Dienst

plan-Beel 631, 633

plan-Cochran 593-4, 600-1

plan-Luns $748-50$

Plantentuin 105

plopper 448

poenale sanctie 103-4, 192

Poetera 304-6, 308-9, 314-6, 324, 359

Politiek Manifest (1945) 423, 426, 530, 656

Politiek Manifest (1959, Manipol) 741

Politieke Inlichtingen Dienst (PID) 167, 204, 227-9, 288-9

politionele acties zie eerste Nederlands offensief, tweede Nederlands offensief

Pontianak 59, 61, 90, 378, 454, 466, 534, 539

POPDA 459, 540

Portugal

- machtsuitbreiding in Azië 2, 14-7

- conflicten met de VOC 21, 25-7, 37, 39

Preanger-stelsel 53, 84, 96

presidentieel besluit X (1945) 422

proclamatie van de onafhankelijkheid van België 85

proclamatie van de onafhankelijkheid van Indonesië

- opstelling 349

- voorlezing 358

Progressieve Concentratie 562, 564

Raad van Indië 26, 47, 58, 70-1, 74, 77, 91-2, 132, 135, 172-3, 208-9, 228, 234, 240, 243-4, 252, 264, 294, 299, 309, 380, 385, 398-9, 407, 437, 442, 575

raciale (wettelijk vastgelegde) discriminatie xvi, 132-5, 138, 155, 221, 243, $288,302,304,392,407,429$

Radicale Concentratie (1918) 172, 190, 241

RAPWI 379-81, 384-6, 401, 411-5, 447

Ratoe Adil zie Djojobojo-legende

Rawagede (razzia in) 563

rechtstreeks bestuurd gebied 47-50, 72, 
$77,79,84,89,96,110,120-2,124-5$, $128,131,237$

Regeeringsreglement 74-5, 77, 92, 96, $132,134-5,138-9,173,191$

regent $76-7$

Rengasdengklok 348

Renville-akkoorden 506, 560-74, 576-9, 583, 587, 589, 592, 594-6, 604, 627, 640, $646-8,661,664,741$

Republiek Indonesië (RI)

- oprichting in 1945 358-60

- herstel in 1950 700-3

Republiek der Verenigde Staten van Indonesië (RVI) 646, 651-2, 654-6, 658-9, 664, 667-72, 689, 692-3, 695-702

Republiek der Zuid-Molukken/Republik Maluku Selatan (RMS) 686, 698-9, 703-6, 708, 725, 742, 749

resident $76-7$

Riouw 61, 91, 458, 467

Roem-Van Roijen-akkoord 622-3, 636-43, $645,647-50,653,664,691$

romusha's 319-20, 328

Rondetafelconferentie (RTC) 622-4, 634$6,638-9,645,652-72,689-90,693,702-$ $4,707,709,711-3,719,741$

rubber $101-2,317,431,519-20,530$

Sabang 100, 128, 396, 542, 665, 686, 755

Sajap Kiri 511, 569, 572

Saparoea 78-9

Sarekat Islam (SI) 151-2, 163-6, 169-70, 172, 175, 177, 180, 184, 186-90, 194, 197-8, 204-6, 217, 225, 231, 240, 250, $259,273,281,410,425,572,715$

schepenboycot in Australië (1945-1949) 387-8, 399, 532, 540, 554, 576, 606

School Tot Opleiding Van Inlandse Artsen (STOVIA) 146, 158-9, 164, 270, 333

Semarang 42, 55, 81, 100-1, 160, 165-6, 169, 181-2, 184, 186, 201, 379, 385-6, 396-7, 406, 411-3, 415, 448, 470, 489, 554

Siak 91, 97-8, 102

Siliwangi-divisie 469, 570, 572, 596, 605

Singapore $80,89,199,202,207,248,257$ 8, 261-3, 278, 282, 295, 310, 344, 370-1,
374, 379, 384, 389-91, 393, 396-7, 405-6, 408, 430, 447, 474, 519, 692, 706, 727, 737

slavernij 33-4, 36, 47, 52, 69, 73, 96, 103, 123

SOBSI 572,717

Sociaal-Democratische Arbeiders Partij (SDAP) 115, 163, 166, 175, 195, 215, 221, 223, 236-7, 242, 303, 365, 368, 395, 408, 441, 443, 465, 537

Soekamiskin (gevangenis in) 133, 215, 225, 292, 295

Soerabaja $11,32,42,55,163-5,197-8$, 201, 209, 217, 221-2, 239, 248, 262-4, 266, 287, 314, 334, 372, 385, 390, 396-7, 401, 411-2, 444, 448, 470-1, 489, 521, $563,596,656,669$

- (strijd in oktober-november 1945) 41320, 426-7, 435, 446

Soerakarta (Solo) 55-6, 71-2, 81-3, 445-6, $458,461-2,542,596,605,649-50,652$

soevereiniteitsoverdracht in Amsterdam $672-3,685$

soevereiniteitsoverdracht in Jogjakarta $672-3$

Solo zie Soerakarta

Spanje 16, 20-1, 25, 33, 37, 39, 123, 158, 240

specerijen $1,13-5,19,21,24,34-8,40-1$, $45,59,70,75,78,84$

Speciale Troepen 517, 691-2

speerpuntenstrategie 603,621

Sriwidjaja xv, 1, 7, 10, 154

Staatkundig Gereformeerde Partij (SGP) $463,536,582,585,669$

Staatsblad-Europeanen 133, 186

Staten-Generaal (regering van de Republiek der Verenigde Nederlanden) 21, 25-6, 28, 33, 39, 47, 59,61

Staten-Generaal (parlement van het Koninkrijk der Nederlanden) 74, 91, 443,472

strafexpedities 111,125

studieclubs 197-8, 203-6, 217, 244

Stuw-groep 211-2, 215, 240, 244, 259, $338,367-8,392,442,464$

Suezkanaal 98, 100 
suiker $45,52-4,84-5,96,100,160,193$, $209,280,317,519-20,530,553$

tabak 85, 96, 101-2, 317, 431, 519, 530

Taman Siswa 185, 217, 245, 280

Tangerang 459, 470

Tentara Keamanan Rakjat (TKR) 404-5, 412-3, 415-7, 427-8, 435-6, 444

Tentara Nasional Indonesia (TNI) 548, $553,559,570,579-80,589-90,595-6$, 603-5, 625-30, 635, 642, 646-7, 649-52, 669-70, 691-3, 695-8

Tentara Republik Indonesia (TRI) 444, 447, 459, 469-71, 478-9, 481, 548

Ternate $13,16-7,24,27,37-9,41,43,48-$ $9,62,79,122,125$

thee $19,45,59,85,100,102,143,317$, 530,553

theosofische beweging 159, 197

Tidore 13, 16-7, 27, 37-9, 48, 79, 111, 661, 663

Tiga A Beweging 289-1, 298, 306-7, 314

Timor 17, 43, 59, 62, 109-10, 123, 188, $207,263,277,335,340,342,467,623$, $657,659-60,703-4,706$

tin $40,101,103,397,431,530$

Tjilatjap ('bloedbruiloft' van) 649

Tjirebon (Cheribon) 11, 42-3, 48, 72, 483, 520

Tonarigumi-stelsel 316, 319, 329

Twapro 658-9

tweede Nederlands offensief (1948)

- aanloop 597-603

- verloop 603-5

- reactie Verenigde Naties 605-8

- reactie Indonesische federalisten 60910

ultimatieve voorstellen van Nederland (mei 1947) 538-43, 546-8

United Nations Commission for Indonesia (UNCI) 608, 622-3, 628, 631, 634-5, 637-9, 648, 653-6, 659, 665

Vaderlandsche Club (VC) 209-10, 212, $228,247-8,253,442,471$

Van Imhoff (KPM-schip) 260-1

Van Mook-lijn 559, 562-4, 566, 572, 589 verbanning $50,83,89,119,134-5,163$, $166,175,195,199,202-3,205,227,230$, $239,250,297,359,383,429$

verbreking diplomatieke betrekkingen Indonesië-Nederland 737, 745, 747, 750

Vereeniging Insulinde 161, 166, 169, 172, 175, 181, 198

Vereeniging van Spoor- en Tramweg Personeel (VSTP) 160, 165-6, 188

Verenigde Naties (VN)

- bemoeienis Algemene Vergadering (AV) met kwestie Nieuw-Guinea 7234, 735-6, 747-50

- eerste bemoeienis Veiligheidsraad (VR) met kwestie Indonesië (februari 1946) 440

- reactie VR op eerste Nederlands offensief (juli-augustus 1947) 555-8

- reactie VR op tweede Nederlands offensief (december 1948) 605-8

Verenigde Oostindische Compagnie (VOC)

- oprichting 25-6

- handelsrijk 34, 39, 43-7, 58

- bestuursstelsel 47-50

- machtsuitbreiding 31-3, 35-43

- einde 59-62

Verenigde Staten van Amerika (VS)

- bemoeienis met conflict tussen Nederland en Republiek Indonesië (1947-1949) 507, 534, 548, 550, 557-8, 561-5, 571, 578, 580, 586, 592-4, 597, $599-602,605-8,625,629,634$

- bemoeienis met conflict over NieuwGuinea (1961-1962) 688, 723, 743, 749-54

Vereniging Nederland-Indonesië (VNI) 369-70, 441-2, 473, 475-6, 509-10, 543

Vietnam 373, 405, 450-1, 525-6, 595, 675, 743,749

Volkspartij voor Vrijheid en Democratie (VVD) 581-2, 585, 599, 602, 663-4, 669, $707,721,744$

Volksraad

- instelling 151-2, 170-1

- uitbreiding bevoegdheden 172-3, 1912 
- 'inlandse meerderheid' 207-9

voorlichting Nederlandse militairen 529

Vreemde Oosterlingen (rechtsbegrip) 133

Werkcomité van het KNIP 422-3, 425-7, $445,477,552,642,668,672-3,701,714$

West-Borneo (federaal 'bijzonder gebied') 534, 539, 556, 583, 609, 695

Westerling-affaire 691-5

'wilde scholen' 147, 184-6, 220, 227, 240

wilde-scholenordonnantie 220-1, 359, 673

zelfbeschikkingsrecht

- van Indonesië 240, 256, 302-3, 357, 394,
$438-9,455,473-4$

- van Indonesische minderheden 65660, 703

- van Papoea's 660, 745, 747-50

zelfbestuursgebieden $48,110,121-3,125$, 128,432

zending (protestantse) 108-9, 116, 441, 473, 707, 737, 748

Zes Punten van Soedirman 570, 646

Zeven Provinciën zie muiterij

Zuid-Celebes 40-1, 61, 73, 79, 82, 90, 125, $128,237,277,324,378,457,466-7,514-$ $9,725,742$

Zuid-Celebesaffaire 517-9

Zuid-Molukkenraad 657, 698

Zwarte Sinterklaas 736-7 